\title{
PENGARUH MODEL PEMBELAJARAN PBL (PROBLEM BASED LEARNING) BERBANTUAN ALAT PERAGA TERHADAP HASIL BELAJAR PADA MATERI GAYA PEGAS
}

\author{
Mirna Hoke, Ferdy Dungus, Tineke Makahinda \\ Fakultas Matematika dan Ilmu Pengetahuan Alam, Universitas Negeri Manado \\ email: mirnahoke176@gmail.com
}

\begin{abstract}
ABSTRAK
Fisika adalah salah satu mata pelajaran yang diajarkan pada jejang pendidikan Sekolah Menengah Atas (SMA). Pembelajaran fisika sering dipandang sebagai ilmu yang abstrak yang disajikan dalam teori yang kurang menarik dan terkesan sulit dikuasai dan dipahami. Untuk mengatasi masalah belajar fisika salah satu model yang diharapkan dapat meningkatkan keaktifan dan hasil belajar siswa adalah dengan menerapkan model pembelajaran Problem based learning (PBL). Penggunaan variasi dalam model pembelajaran PBL dengan alat peraga serta melakukan eksperimen juga dianggap membuat siswa tidak mudah bosan dalam belajar fisika dan membuat materi cenderung mudah dipahami oleh siswa. Untuk itu dilakukan penelitian dengan tujuan untuk mengetahui pengaruh model pembelajaran Problem Based Learning (PBL) berbantuan alat peraga pada materi gaya pegas terhadap hasil belajar siswa. Teknik analisis data dalam penelitian ini mengunakan uji normalitas dan uji hipotesis. Hasil uji normalitas menunjukan data berdistribusi normal, dan hasil uji hipotesis menunjukkan bahwa penerapan model pembelajaran PBL berbantuan alat peraga terbukti berpengaruh terhadap peningkatan hasil belajar siswa.
\end{abstract}

Kata kunci : alat peraga, gaya pegas, hasil belajar

\begin{abstract}
Physics is one of the subjects taught in Senior High School (SMA) education. Physics learning is often seen as an abstract science that is presented in a theory that is less attractive and seems difficult to master and understand. To solve the problem of learning physics, one of the models that is expected to increase the activeness and learning outcomes of students is to apply the Problem Based Learning (PBL) learning model. The use of variations in the PBL learning model with teaching aids and conducting experiments is also considered to make students not easily bored in learning physics and makes the material tend to be easily understood by students. For this reason, a study was conducted with the aim of knowing the effect of the Problem Based Learning (PBL) learning model assisted by teaching aids on the material of spring force on student learning outcomes. The data analysis technique in this research is using normality test and hypothesis testing. The results of the normality test showed that the data were normally distributed, and the results of the hypothesis test showed that the application of the PBL learning model assisted by teaching aids proved to have an effect on improving student learning outcomes.
\end{abstract}

Keywords : : properties, spring style, learning outcomes 


\section{PENDAHULUAN}

Pendidikan merupakan suatu proses perubahan sikap dan perilaku seseorang dalam upaya mendewasakan manusia melalui proses pembelajaran. Pendidikan juga mempunyai peranan penting dalam kemajuan suatu negara, karena maju tidaknya suatu negara pada masa yang akan datang dapat dilihat dari mutu pendidikan yang ada di negara tersebut (Jauhary dkk, 2016).

Fisika merupakan ilmu yang dapat menjelaskan berbagai fenomena-fenomena yang ada di kehidupan kita sehari-hari. Di dalam kehidupan sehari-hari banyak fenomena-fenomena menarik yang memiliki konsep fisika yang dapat dikaji dan dikembangkan sebagai sebuah pengembangan perangkat pembelajaran untuk siswa disekolah. Mata pelajaramn fisika adalah satu mata pelajaran alam rumpun sains yang dapat mengembangkan kemampuan berfikir analitis idnuktif dan deduktif dalam menyelesaikan masalah yang berkaitan dengan peristiwa alam sekitar,baik secara kualitatif dengan mengunakan matematika, serta dapat mengembangkan pengetahuan, keterampilan, dan sikap percaya diri (Kurikulum 2004).

Berdasarkan hasil wawancara dengan sebagian siswa di sekolah SMK Anugrah Tataaran Patar kebanyakan dari siswa mengatakan bahwa "Fisika sulit dan membosankan". Hal ini menjadi tugas rumah bagi guru bagaimana mencari solusi yang tepat untuk mengatasi anggapan dari setiap siswa bahwa fisika itu sulit sehingga hasil belajar siswa rendah, variasi pengunaan media pembelajaran masih kurang dan alat laboratorium untuk materi pegas tidak tersedia. Oleh karena itu salah satu usaha yang harus dilakukan guru untuk meningkatkan hasil belajar siswa adalah melalui penggunaan model pembelajaran dan metode pengajaran yang tepat pada materi yang di ajarkan sehingga siswa dapat belajar dengan suasana yang menyenangkan.

Untuk mengatasi masalah belajar fisika, salah satu model yang diharapkan dapat meningkatkan keaktifan dan hasil belajar siswa adalah dengan menerapkan model pembelajaran PBL (Problem Based Learning). Model pembelajaran PBL atau pembelajaran berbasis masalah inovasi dapat diterapkan pada pembelajaran fisika adalah mengunakan model PBL (Problem Based Learning).
Pembelajaran berbasis masalah menurut Tan dan Rusman (2012) menyebutkan "PBL merupakan penggunaan berbagai macam kecerdasan yang diperlukan untuk melakukan konfrontasi terhadap tantangan dunia nyata, kemampuan untuk menghadapi segala sesuatu yang baru dan kompleksitas yang ada." Model ini mengharuskan siswa untuk mempersiapkan segala hal yang dibutuhkan sebelum pelajaran dimulai kemudian memberikan semangat belajar melalui apersepsi pada materi yang akan dipelajari serta menyampaikannya secara singkat dengan tujuan siswa menemukan konsep materi secara mandiri setelah melakukan diskusi hasil berfikir dipresentasikan. Oleh adanya pengalaman belajar kemampuan intelegensi siswa dapat berkembang dengan baik. Setelah intelegensi berkembang dengan baik, guru memberikan latihan untuk mengukur tingkat kepahaman siswa melalui hasil belajar, setelah selesai melakukan tahapan latihan soal, siswa diharapkan dapat menarik kesimpulan materi yang benar secara mandiri. Dengan demikian model pembelajaran PBL (Problem Based Learning), akan memberikan kontribusi besar pada siswa dimana siswa mampu menguasai dan memahami suatu konsep fisika.

Untuk membuat proses belajar mengajar lebih menarik sehingga siswa tidak mudah bosan dalam belajar fisika dengan adanya variasi dalam model pembelajaran maka model pembelajaran PBL ini juga disertai dengan alat peraga serta melakukan eksperimen (praktikum). Sudjana (2009) menyebutkan bahwa alat peraga adalah suatu alat yang bertujuan membantu guru agar proses belajar mengajar siswa lebih efektif. Proses belajar mengajar ditandai dengan adanya beberapa unsur antara lain tujuan, bahan, metode dan alat, serta evaluasi. Unsur metode dan alat peraga merupakan unsur yang tidak bisa dilepaskan dari unsur lainnya yang berfungsi sebagai cara atau teknik untuk mengantarkan sebagai bahan pelajaran agar sampai tujuan. Dalam pencapain tersebut, alat bantu atau alat peraga memegang peranan yang penting sebab dengan adanya alat peraga ini bahan dengan mudah dapat dipahami oleh siswa. Dalam proses belajar mengajar alat peraga dipergunakan dengan tujuan membantu guru agar proses belajar siswa lebih efektif dan efisien. 
Gaya pegas termasuk dalam salah satu konsep penting yang dipelajari di fisika. Gaya pegas termasuk konsep dasar yang digunakan untuk mempelajari gerak suatu benda dalam kehidupan sehari-hari. Oleh sebab itu konsep gaya pegas dipahami dengan baik oleh siswa, walaupun Alat di laboratorium untuk materi gaya pegas tidak tersedia.

Gaya pegas adalah gaya yang dihasilkan oleh kerja benda elastis. Contoh gaya pegas terhadap pada katepel dan busur panah. Karet elastis pada katepel dapat digunakan untuk melontarkan batu kecil sedangkan tali pada busur panah dapat digunakan untuk melesatkan anak panah (Erlangga 2018). Elastisitas adalah sifat dari benda yang cenderung akan kembali ke bentuk semula setelah mengalami perubahan bentuk, pegas bertambah panjang atau bertambah pendek jika diberi gaya maka dari sini dapat dicari konstanta pegas secara statis. Ketika pegas diberi usikan maka sistem akan mengalami getaran. Dari waktu getaran dapat dihitung periode dan dari periode dapat dihitung konstanta pegas secara dinamis.

Dengan demikian, penggunaan materi gaya pegas dengan menggunakan model pembelajaran PBL ini diharapkan mampu mengatasi kesulitan belajar siswa dan dapat meningkatkan pemahaman konsep yang lebih mendalam pada diri siswa serta mampu melatih kemampuan dan keterampilan siswa.

Berdasarkan latar belakang masalah di atas maka penelitian dengan judul Pengaruh model pembelajaran PBL (Problem Based Learning) berbantuan alat peraga pada meteri gaya pegas terhadap hasil belajar siswa T.P 2018/2019.

\section{METODE PENELITIAN}

Jenis penelitian yang digunakan adalah Posttest-only Control Design yaitu meneliti pengaruh perlakuan terhadap perilaku yang timbul sebagai akibat dari adanya perlakuan tertentu (sugiyono 2014).

\section{Tahapan Penelitian}

Penelitian ini mencakup 3 tahapan yaitu

(1) tahap observasi/penelitian awal, (2) perancangan pembelajaran melalui perumusan konsep-konsep fisika terhadap eksplorasi fakta/fenomena, (3) implementasi rancangan pembelajaran.

\section{Teknik Pengambilan Data}

Teknik pengambilan data mengunakan penilaian terhadap instrumen melalui test tertulis (posttest) pada setiap pertemuan dengan perlakuan: treatment 1, penggunaan Problem Based Learning tanpa adanya alat peraga dan treatment 2, penggunaan Problem Based Learning dengan menggunakan alat peraga.

\section{Teknik Analisis Data}

Uji normalitas yang di gunakan untuk mengetahui data sampel berasal dari populasi yang berdistribusi normal atau tidak.

Uji hipotesis Untuk mengetahui pengaruh model pembelajaran PBL berbantuan alat peraga terhadap hasil belajar siswa di analisis dengan SPSS menggunakan uji t-Test: Paired Two Sample for Means. Hasil Uji Paired Sample tersebut ditentukan oleh nilai signifikansinya. Nilai ini menentukan keputusan yang diambil dalam penelitian:

Nilai signifikansi (2-tailed) $<0,05$ menunjukan adanya perbedaan yang signifikan antara variabel awal dengan variabel akhir. Ini menunjukan terhadap perbedaan perlakuan yang diberikan pada masing-masing variabel. Nilai signifikansi (2-tailed) > 0,05 menunjukan tidak terdapat perbedaan yang signifikan antara variabel awal dengan variabel akhir. Ini menunjukan tidak terdapat pengaruh yang bermakna terhadap perbedaan perlakukan yang diberikan pada masing-masing variabel.

\section{HASIL DAN PEMBAHASAN Hasil \\ Deskripsi Hasil Penelitian}

Penelitian ini dilakukan di SMK Anugrah Tataaran Patar. Penelitian ini dilaksanakan mulai tanggal 29 Oktober - 6 November 2019. Data yang digunakan diambil dari satu kelas yaitu kelas XI yang dalam pembelajarannya untuk treatment I: $1 / 2$ jam pembelajaran hanya menggunakan model PBL(Problem Based Learning)dan treatment II: pada $1 / 2$ jam pembelajarannya ditambah dengan alat peraga. Pada masing-masing kedua jam pembelajaran tersebut, pada akhir dari jam pembelajaran treatment I dan treatment II dilakukan test untuk mendapatkan hasil post test. Hasil tersebut dimaksudkan untuk melihat peningkatan hasil belajar siswa dengan menggunakan PBL (Problem Based Learning) tanpa alat peraga dan penggunaan $\mathrm{PBL}$ 
(Problem Based Learning) dengan alat peraga sehingga dapat terlihat Pengaruh Model Pembelajaran PBL (Problem Based Learning) Berbantuan Alat Peraga Pada Materi Gaya Pegas Terhadap Hasil Belajar Siswa.

Tabel 1 Rangkaian Perlakuan

\begin{tabular}{|c|c|c|}
\hline Tahap & $\begin{array}{l}\text { Treatmen } 1 \text { (tidak } \\
\text { mengunakan alat } \\
\text { peraga) }\end{array}$ & $\begin{array}{l}\text { Treatmen } 2 \\
\text { (mengunakan } \\
\text { alat peraga) }\end{array}$ \\
\hline $\begin{array}{l}\text { Kegiatan } \\
\text { Pendahulu } \\
\text { an }\end{array}$ & $\begin{array}{l}\text { Guru menyajikan } \\
\text { materi dengan } \\
\text { mengunakan } \\
\text { model } \\
\text { pembelajaran } \\
\text { PBL tanpa } \\
\text { mengunakan } \\
\text { berbantuan alat } \\
\text { peraga. }\end{array}$ & $\begin{array}{l}\text { Guru } \\
\text { menyajikan } \\
\text { materi dengan } \\
\text { mengunakan } \\
\text { model } \\
\text { pembelajaran } \\
\text { PBL berbantuan } \\
\text { alat peraga. }\end{array}$ \\
\hline $\begin{array}{l}\text { Kegiatan } \\
\text { Inti }\end{array}$ & $\begin{array}{ll}\text { - Siswa } \\
\text { dibagi } \\
\text { dalam } \\
\text { kelompok, } \\
\text { masing- } \\
\text { masing } \\
\text { terdiri atas } 3 \\
\text { orang. } \\
\text { - Guru } \\
\text { menyajikan } \\
\text { materi } \\
\text { dengan } \\
\text { tidak } \\
\text { mengunaka } \\
\text { n alat } \\
\text { peraga. } \\
\text { Memberika } \\
\text { n LKS } \\
\text { kepada } \\
\text { cicwa }\end{array}$ & 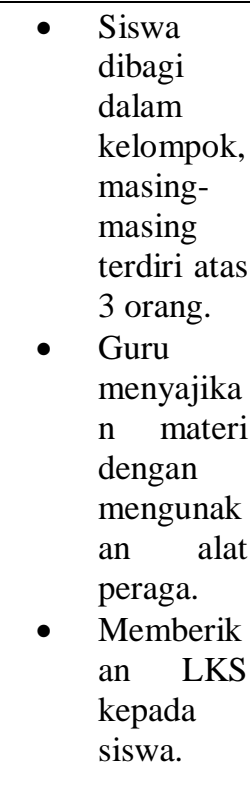 \\
\hline
\end{tabular}

\begin{tabular}{lll}
\hline Kegiatan & Bersama siswa & Bersama siswa \\
penutup & menyimpulkan/ & menyimpulkan/ \\
& mengevalausi & mengevaluasi \\
& proses & proses \\
& berlangsungnya & berlangsungnya \\
& kegiatan & kegiatan \\
& pembelajaran & pembelajaran \\
& pada materi gaya & pada materi \\
& pegas. & gaya pegas. \\
\hline
\end{tabular}

Pembelajaran yang dilakukan ke siswa dilaksanakan sebanyak 3x pertemuan dengan ringkasan skor nilai siswa untuk treatmen 1 dan treatment 2 sebagai berikut:

Tabel 2 Ringkasan Skor Siswa Untuk Treatment 1

\begin{tabular}{|c|c|c|c|c|c|}
\hline \multirow{2}{*}{ No. Subjek } & \multicolumn{3}{|c|}{$\begin{array}{l}\text { Skor Nilai } \\
\text { Treatmen } 1\end{array}$} & \multirow{2}{*}{ Jumlah } & \multirow{2}{*}{$\begin{array}{l}\text { Rata-rata } \\
\text { Skor Nila }\end{array}$} \\
\hline & P1 & P2 & P3 & & \\
\hline 1 & 40 & 55 & 58 & 153 & 51 \\
\hline 2 & 30 & 50 & 60 & 140 & 47 \\
\hline 3 & 30 & 65 & 65 & 160 & 53 \\
\hline 4 & 40 & 60 & 65 & 165 & 55 \\
\hline 5 & 50 & 70 & 75 & 195 & 65 \\
\hline 6 & 40 & 60 & 65 & 165 & 55 \\
\hline 7 & 30 & 60 & 70 & 160 & 53 \\
\hline 8 & 50 & 70 & 70 & 190 & 63 \\
\hline 9 & 46 & 60 & 65 & 171 & 57 \\
\hline 10 & 30 & 60 & 65 & 155 & 52 \\
\hline 11 & 46 & 60 & 65 & 171 & 57 \\
\hline 12 & 50 & 65 & 70 & 185 & 62 \\
\hline 13 & 40 & 50 & 55 & 145 & 48 \\
\hline 14 & 30 & 55 & 65 & 150 & 50 \\
\hline 15 & 30 & 75 & 70 & 175 & 58 \\
\hline & mlah & & & 2480 & 827 \\
\hline & Sko & Min & & & 47 \\
\hline & Skor & Max & & & 65 \\
\hline & ata-R & ta $N$ & & & 55 \\
\hline Sta & ndar & levia & i (S) & & 5.37 \\
\hline & Varia & Is $(S$ & & & 28.88 \\
\hline
\end{tabular}

Tabel 3 Ringkasan Skor Siswa Untuk Treatment 2

\begin{tabular}{|c|c|c|c|c|c|}
\hline \multirow[t]{2}{*}{ No.subjek } & \multicolumn{3}{|c|}{$\begin{array}{l}\text { Skor Nilai } \\
\text { Treatmen } 2\end{array}$} & \multirow[t]{2}{*}{ Jumlah } & \multirow{2}{*}{$\begin{array}{l}\text { Rata-rata } \\
\text { Skor Nilai }\end{array}$} \\
\hline & P1 & P2 & P3 & & \\
\hline 1 & 72 & 76 & 72 & 220 & 73 \\
\hline 2 & 80 & 76 & 76 & 232 & 77 \\
\hline 3 & 80 & 85 & 80 & 245 & 82 \\
\hline 4 & 80 & 85 & 80 & 245 & 82 \\
\hline 5 & 90 & 92 & 100 & 282 & 94 \\
\hline 6 & 70 & 76 & 76 & 222 & 74 \\
\hline 7 & 80 & 85 & 80 & 245 & 82 \\
\hline 8 & 92 & 85 & 90 & 267 & 89 \\
\hline 9 & 72 & 76 & 72 & 220 & 73 \\
\hline 10 & 80 & 85 & 80 & 245 & 82 \\
\hline 11 & 80 & 85 & 80 & 245 & 82 \\
\hline 12 & 90 & 92 & 90 & 272 & 91 \\
\hline 13 & 72 & 76 & 72 & 220 & 73 \\
\hline
\end{tabular}




\begin{tabular}{cccccc}
\hline 14 & 70 & 76 & 76 & 222 & 74 \\
\hline 15 & 70 & 92 & 90 & 252 & 84 \\
\hline \multicolumn{3}{c}{ Jumlah } & & 3634 & 1211 \\
\hline Skor Min. & & 73 \\
\hline Skor Max & 94 \\
\hline Rata-Rata Nilai & 81 \\
\hline Standar deviasi (S) & 6.68 \\
\hline & Varians (S2)
\end{tabular}

Skor nilai rata-rata dari siswa untuk seluruh pertemuan yaitu $3 \mathrm{x}$ proses pertemuan dalam proses pembelajaran sebagai berikut:

Tabel 4 Skor Nilai Rata-rata 3x Pertemuan Skor Nilai Rata-rata

\begin{tabular}{cc}
\hline Treatmen 1 & Treatmen 2 \\
\hline 55 & 81 \\
\hline
\end{tabular}

Untuk mempermudah dalam melihat pengaruh PBL (Problem Based Learning) berbantu alat peraga terhadap peningkatan skor nilai hasil belajar siswa, disajikan dalam grafik berikut:

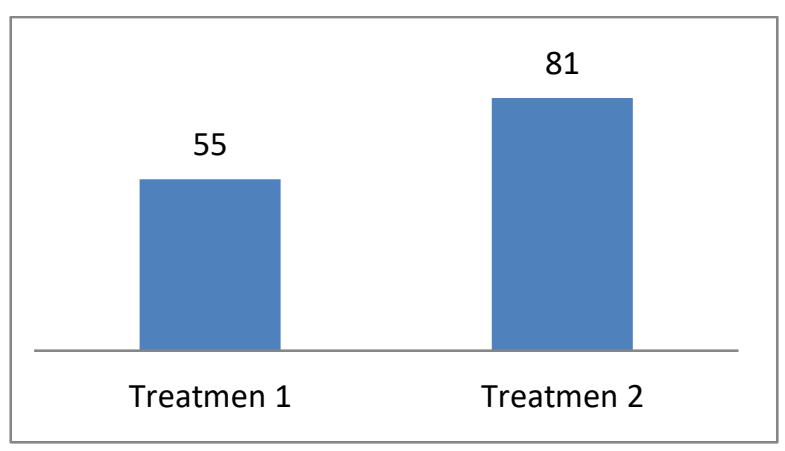

Gambar 1 Grafik Nilai Rata-rata

\section{Uji Normalitas Menggunakan Uji Liliefors}

Hasil uji data normalitas diambil dari skor nilai posttest pada treatmen 1 dan treatmen 2 dengan menggunakan uji liliefors dengan taraf nyata $(\alpha)=0.05$, sebagai berikut:

Tabel 5 Uji Normalitas Untuk Treatment 1

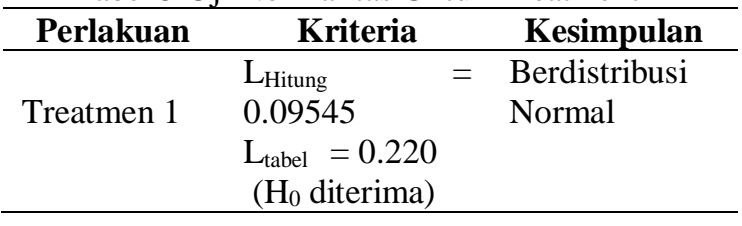

Tabel 6 Uji Normalitas Untuk Treatment 2

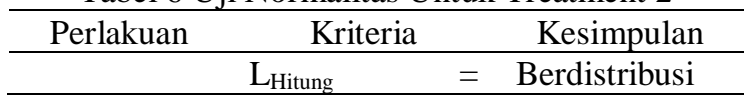

\begin{tabular}{lll}
\hline Treatmen 2 & 0.177432 & Normal \\
& $\mathrm{L}_{\text {tabel }}=0.220$ & \\
& $\left(\mathrm{H}_{0}\right.$ diterima $)$ & \\
\hline
\end{tabular}

Dari kedua data diatas dapat dilihat bahwa nilai $\mathrm{L}_{\text {hitung }}<\mathrm{L}_{\text {tabel }}$ maka dengan demikian skor nilai kedua data tersebut berdistribusi normal.

\section{Uji Hipotesis}

Untuk pengujian Hipotesis menggunakan statistik uji- $t$ dengan T-Test Paired Two Sample Mean adalah sebagai berikut.

- Nilai signifikansi (2-tailed) $<0,05$ menunjukan adanya perbedaan yang signifikan antara variabel awal dengan variabel akhir.

- Nilai signifikansi (2-tailed) >0,05 menunjukan tidak terdapat perbedaan yang signifikan antara variabel awal dengan variabel akhir.

Uji t-Test: Paired Two Sample for Means sebagai berikut:

Paited Samples Siditistics

\begin{tabular}{|c|c|c|c|c|}
\hline & Wean & N & M Deriation & $\begin{array}{c}\text { S4 Eidi } \\
\text { Nation }\end{array}$ \\
\hline Pairl Trabament & 5507 & 15 & 539 & 1382 \\
\hline Trathen 2 & 600 & 15 & 606 & 1969 \\
\hline
\end{tabular}

Gambar 2 Tangkapan layar Perhitungan Paired Sample Statistics melalui aplikasi SPSS
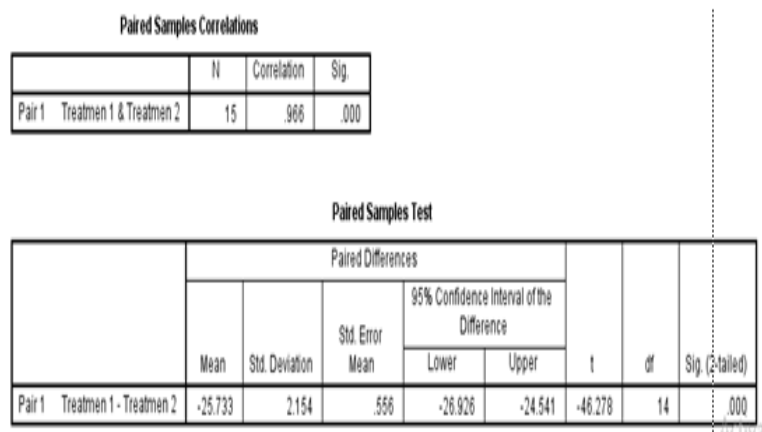

Gambar 3 Tangkapan layar Perhitungan Paired Sample Correlations dan Paired Samples Test melalui aplikasi SPSS

Dengan menggunakan SPSS, maka dapat dilihat pada data diatas diperoleh:

- Treatmen 1 mempunyai nilai rata-rata (mean) 55,07 dari 15 data. Sebaran data (Std. Deviation) yang diperoleh adalah 5,351 dengan standar error 1,382. 
- Treatmen 2 mempunyai nilai rata-rata (mean) 80.80 dari 15 data. Sebaran data (Std. Deviation) yang diperoleh 6,826 dengan standar error 1,763.

Hal ini menunjukkan Skor nilai dari siswa dengan pemberian Treatmen 2 lebih tinggi dari pada Skor nilai siswa yang diberikan Treatmen 1.

\section{Pembahasan}

Penelitian ini merupakan penelitian yang dalam penerapannya hanya menggunakan Posttest-only Control Design pada satu kelas yaitu kelas XI di SMK Anugrah Tataaran Patar dengan diberlakukan 2 treatmen yang berbeda dalam waktu yang sama untuk per pertemuan pembelajaran. treatmen 1 merupakan pemberian perlakuan dengan model Problem Based Learning (PBL) tanpa alat peraga dan treatmen 2 merupakan pemberian perlakuan berbantu alat peraga. Pada akhir pemberian Treatmen 1 dan Treatmen 2 dilakukan posttest dan diperoleh Skor nilai rata-rata siswa yaitu 55 dan 81. Berdasarkan skor nilai tersebut dapat dilihat bahwa skor nilai saat diberikan perlakuan treatmen 1 lebih rendah dibandingkan dengan saat diberikan perlakuan untuk treatmen 2. Pada saat diberikan perlakuan dengan Model Problem Based Learning berbantu alat peraga yaitu treatmen 2, skor nilai siswa terlihat menjadi meningkat dari sebelumnya. Penelitian ini menggunakan uji hipotesis t-Test: Paired Two Sample for Means dengan SPSS dan diperoleh nilai signifikansi (2-tailed) $<0,05$ yaitu $0,000<$ 0,005 . Hasil tersebut menunjukkan penerapan model pembelajaran Problem Based Learning (PBL) berbantu alat peraga terbukti berpengaruh terhadap hasil belajar siswa. Penggunaan Model Problem Based Learning (PBL) berbantu alat peraga mendorong siswa untuk belajar secara aktif, mendorong terciptanya kolaboratif, mampu meningkatkan kualitas pendidikan, membuat proses belajar lebih menarik perhatian siswa, mempercepat proses belajar mengajar atau dengan kata lain menggunakan Problem Based Learning (PBL) berbantu alat peraga, hasil belajar yang akan dicapai akan tahan lama diingat siswa, sehingga pelajaran mempunyai nilai tinggi (Jiniarti, 2015). Hasil yang peneliti peroleh tersebut juga dinyatakan dalam penelitian Widia Astuti, 2019 mengenai Pengaruh Model Problem Based Learning (PBL) Berbantuan
Alat Peraga Terhadap Hasil Belajar Siswa Pada Konsep Fluida Statis, dalam penelitiannya membuktikan Problem Based Learning (PBL) berbantu alat peraga berpengaruh terhadap hasil belajar siswa.

Abanikannda (2016) Penelitian yang membandingkan pendekatan Problem Based Learning (PBL) dengan pembelajaran konvensional ini memiliki mengungkapkan bahwa pendekatan Problem Based Learning (PBL) lebih efektif dalam hal prestasi siswa terhadap fisika. Ini menyiratkan bahwa menggunakan Problem Based Learning (PBL) meningkat siswa untuk memperoleh keterampilan yang mereka butuhkan untuk digunakan dalam kehidupan sehari-hari mereka seperti kerja sama, analisis, komunikasi.

\section{KESIMPULAN}

Berdasarkan hasil penelitian dan pembahasan dapat disimpulkan bahwa terdapat Pengaruh Problem Based Learning berbantu alat peraga terhadap hasil belajar siswa terlihat melalui uji hipotesis dan skor nilai siswa yang diperoleh dari perlakuan dengan 2 treatmen yang berbeda. Pada treatmen dengan model Problem Based Learning berbantu alat peraga, skor nilai siswa mengalami peningkatan rata-rata skor nilai seluruh siswa yaitu 81 dibanding skor nilai sebelumnya yang diberi perlakuan dengan menggunakan model Problem Based Learning saja yaitu hanya 55 .

\section{REFERENSI}

Abanikannda. 2016. Influence of ProblemBased Learning In Chemistry On Academic Achievement of High School Students In Osun State, Nigeria. International Journal of Education, Learning and Development Vol. 4, No.3, pp. 55-63, April 2016.

Astuti, Widia. Pengaruh Model Problem Based Learning (PBL) Berbantuan Alat Peraga Terhadap Hasil Belajar Siswa Pada Konsep Fluida Statis. Fakultas Ilmu Tarbiyah dan Keguruan (FITK) Universitas Islam Negeri Syarif Hidayatullah, Jakarta

Jiniarti, Baiq Ewik, dkk. Implementasi Model Problem Based Learning BerbantuanAlat Peraga untuk Meningkatkan Aktivitas dan Hasil Belajar Fisika Siswa Kelas VIII 
SMPN 22 Mataram Tahun Pelajaran 2014/2015. Jurnal Pendidikan Fisika dan Teknologi. Vol. 1 (3), 2015.

Sudjana. N. 2009. Penelitian Hasil Belajar Mengajar. Bandung: Remaja Rosdakarya 2012. Penelitian Hasil Proses Belajar Mengajar. Bandung : Remaja Rosda Karya.

Sugiyono. (2014). Metode Penelitian Pendidikan Pendekatan Kuantitatif, Kualitatif, dan $R \& D$. Bandung: Alfabeta Suliyanti, dkk. Penerapan Model PBL Menggunakan Alat Peraga Sederhana Terhadap Hasil Belajar Peserta Didik. Jurnal Currica. Vol. 3 (01).

Tan dalam Rusman. (2012). Model-model pembelajaran. Depok: PT.Rajagrafindo Persada

Trianto (2009). Mendesain Model Pembelajaran Progresif. Surabaya : Kencana 